\title{
Entre o Trauma e a Performance: Estratégias para romper com o passado de violência e coletivizar a memória
}

\author{
Marta Haas ${ }^{1}$ \\ Universidade Federal do Rio Grande do Sul - UFRGS, Porto Alegre/RS, Brasil \\ E-mail: martitahaas@gmail.com \\ Gilberto Icle ${ }^{2}$ \\ Universidade Federal do Rio Grande do Sul - UFRGS, Porto Alegre/RS, Brasil \\ E-mail: gilbertoicle@gmail.com
}

\begin{abstract}
Este artigo busca investigar estratégias performáticas que contribuem na busca por reparação e ruptura com o passado de violência e sofrimento relacionado a regimes militares no sul do continente americano. Para tanto, analisa-se alguns atributos performáticos do trauma e do testemunho, assim como exemplos de performances, movidas pelo trauma na América Latina. Propõe-se que o trauma se articula em performance como dispositivo para uma reelaboração criativa que possibilita coletivizar a memória.
\end{abstract}

Palavras-chave

Performance. Trauma. Testemunho. Memória. América Latina.
The following article seeks to investigate performance strategies as a mode of reparation and rupture with the past of violence and suffering related to military regimes in South America. It intends to analyze some performance attributes of trauma and testimony, as well as examples of performances, driven by trauma in Latin America. It is proposed that trauma could be understood in performance as a device for a creative re-elaboration of the past, which could make memory as something collective.

Performance. Trauma. Testimony. Memory. Latin America. 
Na intersecção entre os Estudos da Performance e os Estudos do Trauma, alguns autores - tais como Diana Taylor (2006, 2009), Patrick Duggan e Mick Wallis (2011), Guy Undrill (2000) - têm chamado a atenção para o caráter performático do trauma e de sua transmissão, realizada por meio do testemunho. Optamos aqui por usar performático em vez de performativo, para distinguir do domínio discursivo e marcar a forma adjetiva da performance, seguindo a distinção delineada por Diana Taylor. Ela diz:

[...] em O Arquivo e o Repertório cunhei o termo 'performático' (do espanhol performático) para denotar o domínio não discursivo da performance e diferenciá-lo do domínio 'performativo', que, como teorizado por J. L. Austin, passou a significar uma linguagem que age, que faz alguma coisa. Uso 'performance', de modo geral, para sinalizar condutas reiteradas, 'realizadas duas vezes', que incluem não apenas teatro e dança ou recitais musicais, mas também outros atos convencionais incorporados, como funerais, rituais e movimentos de protesto que são tomados da vida cotidiana. (TAYLOR, 2006, p. 1677, tradução nossa).

Analisaremos alguns desses atributos performáticos do trauma (a repetição, a copropriedade, o real e o performativo) para vislumbrar como eles contribuem na busca por reparação e ruptura com o passado de violência e sofrimento. Essas características serão exemplificadas com algumas performances que buscam coletivizar a memória traumática relacionada à violência de Estado perpetrada em regimes autoritários no sul do continente americano ${ }^{3}$.
Ao falar sobre sua natureza repetitiva, Patrick A repetição, a conduta ${ }^{4}$ reiterada Duggan e Mick Wallis salientam que, embora tenha sido historicamente associado à lesão física, o trauma é hoje mais comumente configurado dentro da psicopatologia. Segundo essa visão, as alucinações traumáticas são descritas como o retorno perpétuo de um evento doloroso que se recusa a ser vivenciado como passado. A teoria do trauma, segundo os autores, sugere essa inclinação repetitiva no sofrimento traumático em si: "[...] o sintoma do trauma é um ensaio, re-apresentação, re-performance da experiência do evento traumático, que irrompe espontaneamente na vida cotidiana do sofredor" (DUGGAN; WALLIS, 2011, p. 2, tradução nossa). Como a experiência traumática implica duas ocorrências psiquicamente ligadas - o evento traumático e seus sintomas -, os sobreviventes ficam presos em um padrão de repetição cíclica e incompreensível.

Ao seguir a pesquisadora dos Estudos do Trauma Cathy Caruth, Duggan e Wallis afirmam que o evento traumático só é acessível mediante esses retornos psíquicos atrasados, os sintomas. $\mathrm{O}$ evento que origina o trauma entorpece os sentidos, uma vez que o corpo está preocupado apenas em lidar com o imediatismo do impacto. Somente após um período de latência esse impacto, com efeito, é sentido e, então, reprimido ou rejeitado. O evento traumático e o sintoma provocam uma espécie de curto-circuito que colapsa o tempo passado e presente, fazendo o sofredor reviver o passado sem distância e sofrendo novamente.
1 Bolsista Doutorado CAPES. O presente trabalho foi realizado com apoio da Coordenação de Aperfeiçoamento de Pessoal de Nível Superior Brasil (CAPES) - Código de Financiamento 001.

\section{Bolsista de Produtividade 1-D do CNPq.}

3 Para uma discussão sobre "a performance como memória encarnada" e a tentativa de "alterar o lugar comum da memória oficial", veja o trabalho de Cadús (2020).
4 Preferimos traduzir "restoration of behavior" (SCHECHNER, 2013, p. 28) como "conduta restaurada" e não como "comportamento", ainda que esta última seja a tradução mais corrente no Brasil. Tal escolha se deve apenas ao fato de tentar evitar compreender "comportamento" como prática individual. Assim, "conduta" pode nos ajudar a lembrar que se trata de uma prática social. 
Sobre essa natureza repetitiva do trauma, Diana Taylor afirma que a memória traumática não pode ser organizada ou acessada em um nível linguístico, ou seja, por palavras e símbolos. Ela sempre se manifesta de forma visceral, por meio de "[...] sintomas corporais, re-encenações e repetições. O fato de não podermos separar o trauma do estresse pós-traumático aponta a centralidade dos efeitos reiterados que constituem essa condição" (TAYLOR, 2006, p. 1675, tradução nossa). Ainda segundo Taylor, algumas das características que Richard Schechner (2013, p. 36, tradução nossa) utiliza para definir a performance - "nunca pela primeira vez. Significa: pela segunda a enésima vez. Performance é 'conduta reiterada'" - valem igualmente para o trauma. O trauma nunca é pela primeira vez. Nem todos os ferimentos causam trauma, apenas os que produzem o pós-choque característico. O trauma unicamente é reconhecido pela natureza de suas repetições, nunca é pela primeira vez. Ao seguir essa lógica, nos sintomas do trauma, o evento traumático performa a si mesmo como uma conduta reiterada.

As marchas recorrentes realizadas pelas Madres de Plaza de Mayo buscam enfrentar o traumático, construindo novas subjetividades. Nessas marchas, evidencia-se a natureza repetitiva do trauma e da própria performance. As mães que iniciaram a marcha em 30 de abril de 1977 haviam comprovado a inutilidade dos esforços individuais contra a estrutura do Estado terrorista, seus cúmplices dentro e fora da Argentina, bem como o silenciamento social, político e da mídia. E, conquanto poucas mulheres estivessem presentes na primeira marcha, esse foi um passo inicial significativo na construção de uma nova forma de resistência. Segundo Gorini (2017), foi Azucena Villaflor, liderança das Madres, que posteriormente também foi torturada e desaparecida, quem insuflou as demais mães com as seguintes palavras:

Mães, assim não conseguimos nada. Nos mentem em todas as partes, nos fecham todas as portas. Temos que sair deste labirinto infernal que nos leva a recorrer inutilmente a despachos oficiais, quartéis, igrejas e juízes. Temos que ir diretamente à Plaza de Mayo e ficarmos ali até que nos deem uma resposta. Temos que chegar a ser cem, duzentas, mil mães, até que nos vejam, até que todos se inteirem e o próprio Videla se veja obrigado a nos receber e nos dar uma resposta. (GORINI, 2017, p. 50, tradução nossa).

Assim como o número de desaparecidos foi expandindo de forma assustadora nos meses seguintes, o número de mulheres em marcha aumentou. Desde 1977, todas as quintas-feiras às 15h30, as Madres realizam a "ronda" ao redor da Pirâmide de Maio, o monumento central da praça em frente à Casa Rosada, sede do governo federal argentino.

O lenço branco amarrado à cabeça, feito com tecido de fralda, simbolizando a memória das fiIhas e dos filhos desaparecidos, inicialmente serviu para se reconhecerem. Hoje, o pañuelo branco é símbolo mundial de luta, coragem e resistência. Para a socióloga Laura Zambrino, o pañuelo "[...] conseguiu conjugar todas as categorias 'técnicas' da representação: é ícone, sinal, estandarte, emblema, insígnia, símbolo, marca" (ZAMBRINO apud MUZI, 2018, n.p., tradução nossa).

A força simbólica do pañuelo tornou-se tão expressiva que outros movimentos ou grupos o adotaram como parte de suas táticas de protesto. Mais de 40 anos depois, a Campaña por el aborto legal, seguro y gratuito da Argentina repete o gesto de usar um pañuelo como símbolo, dessa vez verde. Desde 2018 esse pañuelo passou a ser carregado cotidianamente pelas mulheres argentinas que defendem a legalização do aborto. Assim como o pañuelo branco das Madres, funciona como um elemento de reconhecimento e identificação com a luta feminista.

As fotografias também ocupam um lugar fundamental no conjunto de símbolos criados pelas Madres. Diana Taylor analisa as diferentes formas de utilizar a fotografia ao longo da trajetória dos movimentos das Madres, Abuelas e H.I.J.O.S. na Argentina, cada utilização adaptada a um contexto político. No caso das Madres, as fotografias eram uma forma de comprovar a existência daqueles que foram desaparecidos. Segundo a autora, 
[...] quando as Madres foram para as ruas para tornar os desaparecimentos visíveis, elas ativaram as fotografias, performatizando-as. A necessidade de mobilidade, aliada à importância da visibilidade para se ver a distância, determinou a escolha de cartazes muito grandes, porém leves, para serem carregados pelas mulheres em seu desfile ao redor da praça. [....] Ao usar pequenas reproduções dos documentos de identidade no pescoço, as Madres transformaram seus corpos em arquivos, preservando e exibindo as imagens que haviam sido alvo de uma tentativa de apagamento. (TAYLOR, 2013, p. 249-250).

Quando as pessoas classificadas como subversivas eram desaparecidas, as Forças Armadas destruíam também todos os documentos e arquivos relacionados àquelas pessoas. Era como se, ao apagar as evidências documentais de uma pessoa, fosse possível apagar seus rastros e sua própria existência, tirando a credibilidade daqueles que buscavam sua aparição com vida. Por isso o uso da fotografia, sobretudo as fotografias dos documentos de identidade, tiveram grande importância: enquanto as Forças Armadas queriam destruí-las, as Madres utilizavam-nas como prova da existência de suas filhas e filhos. Essas fotografias, exibidas de forma contínua em praça pública sobre o próprio corpo, tornava manifesto o aumento exorbitante de desaparecidos.

O testemunho logo abaixo, de Hebe de Bonfanti, presidente da Asociación Madres de Plaza de Mayo, compilado em reportagem de Martín Fernández Lorenzo (2019), evidencia a disposição dessas mulheres em repetir esse gesto até o fim de suas vidas. Esse esforço surge da compreensão de que, embora suas filhas e filhos jamais regressem, a luta contra o Estado terrorista também é responsabilidade delas.

Marchamos na Plaza de Mayo. Ali nos reunimos com nossos filhos, ali nos sentimos vivas. Desde o primeiro momento nós, Madres, sem sabermos, estávamos educando para a paz. Estávamos caminhando em uma Praça enfrentando a ditadura, fazendo um grande esforço para não ficarmos em uma cama chorando. [...] Quando nos demos conta de que eles não voltariam, tomamos a decisão de não mais deixar a Plaza. Tomamos a decisão de lutar até o último dia de nossas vidas e também entendemos que a luta individual não fazia sentido, que deveríamos assumir a responsabilidade de socializar a maternidade, fazendo de nós mães de todos. (LORENZO, 2019, n. p., tradução nossa).

A persistência desses rituais de protesto contínuo, que ocorrem desde 1977, criou uma poderosa imagem de repetição e familiaridade. A ronda semanal tornou-se um compromisso - não só dessas mulheres, mas de toda a sociedade - com a memória. Tornou-se uma espécie de vigília coletiva, que nos adverte que a dor e o trauma são coletivos e que a responsabilidade para que isso não volte a acontecer é de todos e todas.

\section{A copropriedade, a responsabilidade}

Para Guy Undrill, há um contrato ético assumido pelo sujeito que escuta e testemunha o testemunho do outro: "[...] deve haver uma solicitude de responsabilidade sem cair na tentação de tentar curar, explicar ou aperfeiçoar. Testemunhar implica simplesmente estar com o outro em sua desordem" (2000, p. 135, tradução nossa). Embora seja importante não cair na tentação de curar aquele que testemunha ou de aperfeiçoar e tornar menos confusa sua narrativa, Taylor assinala que dar testemunho requer participação, é "[...] um ato de transferência que ocorre no aqui e agora na presença de um ouvinte que passa a ser um participante e coproprietário do evento traumático" (2006, p. 1676, tradução nossa).

Para exemplificar esse ponto, talvez seja interessante trazer o testemunho de Primo Levi sobre o campo de concentração nazista: "[...] a necessidade de contar 'aos outros', de tornar 'os outros' participantes, alcançou entre nós, antes e depois da libertação, caráter de impulso imediato e violento, até o ponto de competir com outras necessidades elementares" (LEVI, 1988, p. 7-8). A transmissão da memória traumática muitas vezes só acontece por intermédio da performance ao vivo. Isso fica ainda mais nítido se retomarmos a ideia de que as performances operam como práticas corporais que 
transmitem conhecimento e memória coletiva, a partir de condutas reiteradas e interativas. Assim como a performance, para que o testemunho aconteça, é preciso - como atesta a necessidade de Levi - tornar "os outros" participantes. Para um sobrevivente, revela-se uma necessidade elementar contar para as outras pessoas que não passaram por essa experiência, essa seria uma forma de restabelecer um laço com "os outros", de religar-se ao mundo. Quando "o outro" escuta o testemunho do sobrevivente e está com ele em sua desordem e angústia, torna-se coproprietário do terror narrado, participante de uma mesma comunidade. Isso implica, ao mesmo tempo, responsabilidade quanto ao nosso futuro comum.

A ideia de copropriedade e responsabilidade pode ser percebida em diversos protestos em forma de performance motivados pelo trauma. Trazemos como exemplo uma ação convocada pelo Colectivo Sociedad Civil (CSC), do Peru, realizada pela primeira vez numa sexta-feira, 20 de maio de 2000 , uma semana antes do segundo turno das eleições presidenciais. Essa convocação era uma resposta direta à tentativa, em seguida consumada, de Alberto Fujimori, presidente peruano desde 1990, reeleger-se uma terceira vez por meio de uma manobra constitucional. A ação Lava la bandera, segundo Gustavo Buntnix, membro do CSC, consistia em

[...] um ritual participativo de limpeza pátria [...]. Um ato de dignificação dos emblemas nacionais e, ao mesmo tempo, um gesto que propicia transparência e honestidade num processo histórico marcado por graves e obscuras irregularidades. Os instrumentos litúrgicos são mínimos, mas significativos: água (a água purificadora), sabão ([de marca] Bolívar: um militar patriota), e vulgares bacias de plástico (vermelho) colocadas sobre bancos rústicos de madeira [...]. Esses elementos esperam ali todos aqueles que tragam bandeiras peruanas, de qualquer tamanho, mas confeccionadas em tecido, para serem lavadas pelos próprios cidadãos e, em seguida, estendidas em cordas até converter o centro simbólico dos poderes públicos da cidade (palácio, catedral, conselho) num gigantesco varal popular. E a praça pública mais protegida do país numa prolongação do pátio doméstico. (BUNTNIX, 2006, n. p., tradução nossa).

Quatro dias depois da primeira edição, a ação foi realizada na Plaza Mayor de Lima. Foi repetida ritualmente todas as sextas-feiras durantes seis meses, apesar dos vários atos de repressão por parte do governo peruano. Seu potencial em convocar participantes fez com que a ação fosse replicada em outras regiões do país e algumas cidades de outros países.

O convite para as pessoas lavarem a bandeira peruana com água e sabão em praça pública, para em seguida transformar o espaço em um enorme quintal coletivo repleto de varais, foi o estopim para articular e mobilizar uma sociedade paralisada pelo medo, após duas décadas de conflito armado. Foi uma forma de subverter a imposição de um governo autoritário e corrupto, de convocar os cidadãos a ocuparem o espaço público de forma lúdica e livre, sentindo-se participantes de um ritual coletivo e responsáveis pelo processo histórico em pleno curso: o desejo comum de lavar o país da corrupção e da violência perpetuada nos últimos anos. Para lleana Diéguez,

[...] durante algum tempo Lava la bandera transformou um espaço controlado pelas forças oficiais num fórum aberto à expressão e ao encontro lúdico dos corpos. No lugar, que até esse momento estava sob vigilância, misturaram-se os participantes - não mais espectadores - de uma festa, onde o maior símbolo pátrio deixava de ser solene, colocado em situação cotidiana. A bandeira, objeto de honras oficiais, foi manipulada como uma roupa comum, num gesto de destronamento e apropriação popular. (DIÉGUEZ CABALLERO, 2011, p. 97).

Esse ritual coletivo reinventou a forma como os cidadãos peruanos lidavam com o processo político, possibilitando que cada um, ao lavar a bandeira em espaço público, se sentisse vivo no processo político. Novas formas de agir, mais autônomas e ativas - alicerçadas nas ideias de copropriedade e responsabilidade sobre o passado comum e o que está por vir - foram estabelecidas no tecido social. Por decisão coletiva dos partici- 
pantes, a última ação Lava la bandera foi realizada em 24 de novembro de 2000, após ser declarada a vacância da presidência. Em 21 de novembro de 2000, Fujimori havia sido destituído da presidência por "permanente incapacidade moral". Desde 13 de novembro ele se encontrava exilado no Japão, após serem difundidos diversos vídeos que comprovavam a corrupção generalizada de seu governo.

\section{0 real}

O terceiro aspecto performático do trauma é sua relação com o real. Segundo Undrill (2000, p. 133, tradução nossa), "[...] nos Estudos da Performance, o real representa o que é regularmente usado para distinguir a performance da pretensão teatral e ilusória; na psicanálise, o Real forma uma das três ordens conceituais de Lacan". Conforme André Oliveira Costa e Simone Zanon Moschen (2013, p. 437), "[...] o trabalho de Lacan com aquilo que ele denominou de registros Simbólico, Imaginário e Real nos é fundamental para avançar em nossa indagação sobre o sujeito, as formas da alteridade e a modalidade de laço que podemos pensar entre eles". Dentre esses três registros, o Real constitui aquilo que:

[...] resiste à simbolização, mostrando o impossível do saber em totalidade [...], na medida em que as palavras não dão conta de definir por completo [...]. Assim, segundo o neologismo de Lacan, o Real ex-siste ao sentido, quer dizer, ele está fora da inscrição simbólica. (COSTA; MOSCHEN, 2013, p. 446-447).

Dessa forma, se entendermos o real na performance não como uma contraposição à ilusão ou à ficção, mas como a irrupção de algo que não conseguimos elaborar, compreendemos melhor como o real opera na performance e no trauma. Esse real, portanto, não deve ser confundido com a noção de realidade, mas deve ser compreendido como uma experiência que resiste à representação, que é impossível de simbolizar e transmitir. No contexto da performance, consequentemente, o real é aquilo que irrompe nos momentos de surpresa, induzindo o par- ticipante a uma resposta visceral que não pode ser articulada, apenas sentida. Conforme Fiona Sprott,

[...] não posso produzir o real, ele deve ser descoberto por acaso. Ele é isso que a performance não alcança conscientemente, mas que é revelado como estando presente pelo público, demonstrado na maneira como responde. O público deve descobrir o real por si próprio, e nem todo membro do público experimentará um encontro com o real durante uma performance. Pode-se representar um evento ou encontro traumático, mas isso é apenas representação, não uma experiência genuína do real. (SPROTT, 2013, p. 311, tradução nossa).

Tanto nos Estudos da Performance quanto nos Estudos do Trauma existe a dificuldade em narrar um evento. Ao transformar a experiência vivida (seja o evento da performance ou do trauma) em um relato narrativo, algo de indescritivel se perde. Falamos de um inapreensível próprio da performance e que a linguagem não abarca, ainda que possamos falar de efeitos performativos da linguagem (ICLE, 2019). No entanto, isso que é perdido, em alguns sentidos, é mais "real" do que aquilo que é preservado na narrativa. O real, em vista disso, é o que não pode ser conhecido ou falado. É essa qualidade inassimilável que the confere sua qualidade traumática.

O real ligado a um evento traumático é uma falha na linguagem, em que cessam todas as palavras para narrar aquilo que aconteceu, tornando-se objeto de ansiedade, angústia, desespero. Essa ruptura na narrativa de um sujeito, que não encontra palavras para simbolizar, não Ihe permite relembrar o evento traumático como algo que aconteceu no passado. Uma vez que "o sujeito humano é um sujeito falante, quando se nega a fala, a subjetividade é ameaçada" (UNDRILL, 2000, p. 134, tradução nossa). Repetir e performar esse encontro perdido com a fala é uma forma de tentar dominá-lo, de tentar reestabelecer uma narrativa que entenda o evento traumático como passado.

Essa noção de real pode ser percebida na ação de Artur Barrio, intitulada Trouxas Ensanguentadas (T.E.), realizada no Parque Municipal de Belo Ho- 
rizonte, como parte da mostra Objeto e Participação, concretizada entre 17 e 21 de abril de 1970. Conforme o blog cartografiasentimental, na primeira parte ou preparação das T.E., o artista se pôs

[...] a manipular o conteúdo da trouxa sangue, carne em decomposição, ossos, barro, espuma de borracha, pano, cabo (cordas), facas, sacos, cinzel - experimentando, ele próprio, o contato quase direto com os materiais, que traduziu em anotações como 'SUORCHEIROSENSAÇÃO' e 'PELSOBREPEL'. A segunda parte deu-se na manhã seguinte, quando Barrio colocou as 14 T.E. em um 'rio/esgoto', o ribeirão Arrudas, que à época corria abertamente atrás do Parque Municipal, na região central da capital mineira, sendo que a utilização do parque pelos artistas havia sido autorizada, por meio de cartas individuais, pela companhia de turismo do governo, Hidrominas. (ANÔNIMO, 2011, n. p.).

Essa situação/trabalho foi realizada no período mais duro do regime militar brasileiro. Desde o decreto do AI5 em 1968, a censura era extremamente rígida, principalmente aos meios de comunicação e às artes. Também era o período de desmantelamento completo das organizações de luta armada ou de base, logo, ápice da repressão mediante sequestros, torturas, assassinatos, execuções sumárias disfarçadas de resistência e desaparecimentos forçados.

A situação T.E., realizada no espaço público do Parque Municipal de Belo Horizonte, atraiu um grande público e gerou muita tensão. Esse fato resultou na intervenção dos bombeiros e depois da polícia, que acabou apreendendo as trouxas. Artur Barrio permaneceu de forma anônima em meio à multidão e pôde registrar o que aconteceu. Com relação a esse trabalho, ele afirma que busca

[...] o contato com a realidade em sua totalidade, do tudo que é renegado, do tudo que é posto de lado, mais pelo seu caráter contestador; contestação essa que encerra uma realidade radical, pois que essa realidade existe, apesar de dissimulada através de símbolos. (BARRIO apud ANÔNIMO, 2011, n. p.).
As 14 Trouxas Ensanguentadas de Barrio, compostas de diversos materiais em putrefação como sangue, carne em decomposição e ossos, jogadas de uma só vez na beira de um arroio em pleno centro de uma grande cidade, escancaravam aquilo que não podia ser dito. A semelhança hiper-realista com um cenário de desova de corpos conseguiu evocar um trauma coletivo. Conquanto logo tenha sido possível constatar que não se tratavam de restos humanos, a imagem gerada provocou um forte impacto, suspendendo o olhar de todos para algo indeterminado. Embora a cena de desova não fosse "verdadeira", ela possuía essa qualidade inassimilável e real, escancarando os excessos traumáticos próprios daqueles tempos extremados.

\section{O performativo}

O quarto aspecto performático do trauma caracteriza a sua transmissão, por meio do testemunho, como um ato de fala ${ }^{5}$. Na performance, o corpo ocupa um lugar privilegiado, no entanto, a linguagem também cumpre uma importante função. Ao analisar os antecedentes da performance arte, Taylor inclusive afirma que "[...] a linguística, para certos acadêmicos, dá origem à performance como speech act ou atos de fala" (2012, p. 61, tradução nossa). A teoria dos atos de fala teve seu início com o trabalho do filósofo linguista John Langshaw Austin (1911-1960) sobre os performativos e foi continuada por John Roger Searle (1932-). Segundo Schechner,

\begin{abstract}
Austin cunhou a palavra 'performativo' para descrever enunciados como: 'Eu aceito essa mulher como minha legítima esposa' ou 'Batizo esse navio de Rainha Elizabeth' ou 'Peço desculpas' ou 'Aposto dez dólares que amanhã chove' [...]. Nesses casos, como observa Austin, 'dizer algo é fazer algo'. (SCHECHNER, 2013, p. 123, tradução nossa).
\end{abstract}

5 Nos Estudos da Performance há um intenso debate sobre a oposição entre a performance e o arquivo, entre o efêmero e o documental. Tomaremos aqui a posição de contraposição à ideia de que a performance é efêmera e, portanto, nada transmite. Pode-se encontrar um exemplo desse debate no trabalho de Ayerbe (2017). 
Segundo Paulo Ottoni, o ato de fala de Austin é composto por três atos simultâneos, um ato locucionário (no qual se dá a significação), um ato ilocucionário (a realização de ação por meio de um enunciado, como por exemplo "eu prometo...") e um ato perlocucionário (que produz efeito no interlocutor). É por intermédio desses três atos que Austin faz

[...] a distinção entre sentido e força, já que o ato locucionário é a produção de sentido que se opõe à força do ato ilocucionário; estes dois se distinguem do ato perlocucionário, que é a produção de um efeito sobre o interlocutor. (OTTONI, 2002, p. 128).

Conforme Ottoni, Austin assinala três maneiras de distinguir o ato ilocucionário do perlocucionário: assegurar sua apreensão (securing uptake), ter efeito (taking effect) e levar a uma resposta ou sequela (inviting a response). O comentador afirma que a primeira "[...] é a mais importante, uma vez que com o uptake fica mais claro que a referência que vai estar diretamente ligada ao momento da enunciação, não se dá mais ao nível constativo da linguagem, mas numa concepção performativa" (OTTONI, 2002, p. 133-134). Ou seja, o uptake é uma relação que acontece na própria linguagem, quando no momento da enunciação os interlocutores asseguram sua apreensão. O sujeito falante, por conseguinte, não tem sozinho o domínio da significação, ela se constitui na interlocução. É também no momento da enunciação que se constitui o sujeito do ato de fala, que faz parte da linguagem e não deve ser mais confundido com o sujeito falante empírico.

Em face de tais observações, compreendemos por que não é possível um sujeito falante ter controle sobre sua intenção. Sempre podem haver situações inesperadas, surpreendentes, não tencionadas pelo sujeito falante. A intenção, portanto, não é unilateral, mas se realiza juntamente com o interlocutor, por meio do uptake, isto é, assegurando sua apreensão. Para Ottoni (2002, p. 135), "Austin, com a noção de 'uptake', subverte a sua própria teoria até então calcada no papel centralizador do sujeito falante". Dessa forma, o ato de fala acontece somente quando ambos os interlocutores asseguram a sua apreensão.

Essa subversão que o conceito de uptake opera na teoria de Austin é importante para as articulações que Shoshana Felman (2003) estabelece entre a teoria dos atos de fala e a psicanálise, mediante a relação entre corpo e linguagem. $O$ ato de fala, como ato de um corpo falante, é sempre desconhecedor daquilo que produz, pois está sujeito ao inconsciente. A pesquisadora parte da teoria de Austin para investigar o que há de paradoxal e contraditório no ato de prometer, mostrando que o performativo comporta necessariamente sua falha. Toda promessa é uma promessa de consciência, uma vez que postula uma continuidade entre intenção e ato. Todavia, como vimos, a intenção do sujeito falante não governa e controla o ato de fala, ele depende que os interlocutores assegurem sua apreensão (securing uptake). A autora utiliza a noção de corpos falantes, como os atos corporais que excedem a intenção e produzem sentidos diversos daquilo que foi intencionado. Na constituição do ato é impossível separar corpo e linguagem. De acordo com Felman,

[...] se a teoria da performance do corpo falante - dos atos de fala propriamente ditos - está no domínio do performativo, a teoria do escândalo dessa performance entra no domínio da psicanálise. O escândalo consiste no fato de que o ato não é capaz de saber o que ele está fazendo, que a ação (da linguagem) subverte tanto a consciência quanto o conhecimento (da linguagem). $O$ 'inconsciente' é a descoberta não apenas do divórcio ou da brecha radical entre ato e conhecimento, entre constativo e performativo, mas também (e nisso está o escândalo da descoberta final de Austin) a descoberta da indecidibilidade desses elementos e da constante interferência entre eles. Freud descobriu não simplesmente que o ato subverte o conhecimento, mas também que é precisamente a partir da brecha no conhecimento (a quebra no constativo) que o ato obtém seu poder performativo: é o próprio conhecimento, que não pode conhecer a si mesmo, que atua no indivíduo. (FELMAN, 2003, p. 67, tradução nossa). 
Para compreender melhor a questão do performativo, podemos aludir os protestos em forma de performance dos H.I.J.O.S. Eles possuem diversas ações que podemos considerar atos de fala performativos, sobretudo os escraches e a ideia de uma condenação social. Os primeiros escraches na Argentina surgem em 1996, no início da agrupação, para denunciar a impunidade da justiça institucional. As leis de Obediencia Debida ${ }^{6}$ e Punto Final ${ }^{7}$, assim como diversos decretos de indulto ${ }^{8}$, impediam o julgamento dos genocidas argentinos. A palavra escrache vem do lunfardo, gíria falada principalmente na região platense. Significa trazer à luz o que está oculto, desvelar o que o poder esconde.

Os primeiros escraches já tiveram um forte impacto na opinião pública, por romper com as formas tradicionais de fazer política, trazendo para os protestos a alegria, o festivo e o carnavalesco. Com o tempo, outros coletivos artísticos como o Grupo de Arte Callejero (GAC) e o Colectivo Situaciones, além de diversos simpatizantes, passaram a colaborar nas ações. A ideia era fazer com que as pessoas repudiassem os genocidas soltos, questionando a ausência do julgamento legal. A consigna Juicio y Castigo (Julgamento e Punição), gestada pelos H.I.J.O.S., se tornou representativa de toda uma nova geração de ativistas dos direitos humanos. Com essa consigna,

6 A Lei no 23.521/1987, chamada Ley de Obediencia Debida, foi uma disposição legal ditada na Argentina, durante o governo de Raul Alfonsín, que estabeleceu uma presunção de que os feitos cometidos pelos membros das forças armadas durante a chamada guerra suja e o Processo de Reorganização Nacional não eram puníveis por haver agido em virtude de obediência devida.

7 A Lei n 23.492/1986, chamada Ley de Punto Final, foi promulgada na Argentina, durante a presidência de Raul Alfonsín, estabelecendo a paralisação dos processos judiciários contra os autores das detenções ilegais, torturas e assassinatos que ocorreram na etapa de ditadura civil-militar.

8 Os indultos são uma série de dez decretos sancionados, em 1989 e 1990, pelo presidente Carlos Menem, indultando civis e militares que cometeram crimes durante a ditadura civil-militar, incluindo os membros das Juntas Militares, condenados em 1985. Cerca de 1.200 pessoas foram beneficiadas. havia uma dupla aposta: exigir a justiça institucional e, ao mesmo tempo, construir uma condenação social.

A luta por uma construção social de justiça leva à criação de outro lema: Si no hay justicia hay escrache. Essa linha de ação foi aprofundada em 1998, quando foi concebida a Mesa de escrache. Consistia em uma mesa de trabalho, um encontro semanal, realizada em diversos bairros, organizada em rede com diversas organizações sociais. As decisões eram tomadas de forma horizontal, por meio do consenso. Tinha como princípio para a condenação social a ideia de uma memória viva, criadora e em ação.

A consigna Si no hay justicia hay escrache gerou muitos debates na Mesa de escrache, nomeadamente sobre o objetivo da condenação social. Enquanto alguns entendiam a condenação social como um meio para o julgamento e punição, outros sustentavam que era um fim em si mesma. Com a eleição de Nestor Kirchner e a revogação das leis de Obediencia Debida e Punto Final, diversos julgamentos e condenações começaram a acontecer. Isso redundou no acirramento da discussão sobre a função dos escraches e sobre o que é justiça. Para alguns, uma vez que as leis que mantinham a impunidade dos genocidas tinham sido anuladas, os escraches haviam cumprido sua função e não eram mais necessários. Porém, se o escrache é um fim em si mesmo,

[...] o ato de justiça é realizado diretamente por meio da sinalização da casa do escrachado. Nesse sentido se pode ler uma frase que surge da obra teatral que os HIJOS apresentaram em várias oportunidades: 'Que o país seja sua prisão'. Desse modo, o objetivo que essa prática tem é que o bairro conheça a casa do repressor, que saiba quem é o vizinho, qual é sua história. Com essa informação se pretende que a sociedade vá discriminando os repressores. (CUETO RÚA, 2010, p. 174, tradução nossa).

Sob essa perspectiva, é preciso atualizar constantemente o ritual de condenação social, para que a sociedade se aproprie desse mecanismo e mantenha viva a memória social. Assim, distanciam-se das práticas do Poder Judiciário, que 
individualizam os problemas sociais. A justiça é entendida como uma prática coletiva, que abre a possibilidade de um processo de subjetivação política. Conforme o Colectivo Situaciones (2000),

[...] a luta que o escrache expressa vai mais além do estado de direito, não pode ser reabsorvida por este. Se hoje foram presos um, dois, ou dez militares genocidas, os escraches não cessariam. [...] ninguém vai no escrache porque pensa que vai haver justiça, mas porque a justiça está aí. (apud CUETO RÚA, 2010, p. 175, tradução nossa).

Segundo Santiago Cueto Rúa (2010), dentro do próprio coletivo H.I.J.O.S. havia posições diferentes. Alguns corroboravam com a posição do Colectivo Situaciones e viam no escrache a possibilidade de fazer uma justiça paralela à estatal. Embora os escraches fossem uma exigência por justiça, não estavam orientados necessariamente para o Estado. Outros tinham uma visão instrumental e entendiam a condenação social como um passo anterior para a condenação legal. Também havia aqueles que mantinham uma posição intermediária, que viam o escrache como um fim em si mesmo e também como um meio, "[...] no qual se aproveita a riqueza dessa experiência e ao mesmo tempo não se perde de vista o horizonte da condenação institucional a cargo do Estado" (CUETO RÚA, 2010, p. 176, tradução nossa).

À vista de tal reflexão podemos compreender como a consigna Si no hay justicia hay escrache, aliada à noção de uma condenação social, constitui um ato de fala performativo. Se o escrache pode ser um meio e um fim, ao prometer que se não há justiça há escrache, os membros de diversos coletivos performam atos. Eles não descrevem ou representam ações, eles fazem algo, no caso, fazem justiça. Fazem uma justiça que acontece no momento presente e que incorpora o coletivo nesse fazer. A ideia de condenação social por meio do escrache não busca - ou, pelo menos, não apenas - uma resposta institucional do Estado, mas uma construção cotidiana que congrega toda a sociedade. Além disso, ao seguirmos Felman e sua análise psicológica dos atos de fala performativos, percebemos que a justiça pode ser uma capacidade dos corpos falantes. Assim, o debate indefinido sobre o escrache ser um meio ou fim em si mesmo pode ser lido em face ao escândalo provocado pelo domínio performativo, ou seja, de que a ação (da linguagem) subverte tanto a consciência quanto o conhecimento (da linguagem). Os corpos falantes que querem e prometem, muitas vezes sem ter conhecimento disso, fazem justiça.

Ao elencar algumas características performáticas do trauma e do testemunho e buscar exemplos que elucidem essas características, entrevemos diferentes estratégias performáticas utilizadas na América Latina na busca por reparação e ruptura com o passado de violência e sofrimento: a repetição ou conduta reiterada nas ações das Madres de la Plaza de Mayo; a copropriedade e a responsabilidade coletiva exigida na ação Lava la bandera; o real que não pode ser simbolizado na situação Trouxas Ensanguentadas; o performativo contido na consigna Si no hay justicia hay escrache.

Essas estratégias, que incorporam e reelaboram o peso das memórias traumáticas, visam romper com a violência institucional e apontar outras possiblidades de se relacionar e viver em comunidade. Trata-se, portanto, de um processo no qual a performance funciona como uma espécie de catalizador por intermédio do qual podemos coletivizar a memória traumática. Isso significa partilhar, pelo testemunho, a violência. Essa operação de partilha compõe uma rearticulação criativa, coletiva, performática e performativa. Ela possibilita o encontro entre o passado e o presente, reelaborando nos corpos os traumas vividos de maneira coletiva.

\section{Referências}

ANÔNIMO. O significado político nas Trouxas Ensanguentadas, de Barrio. 2011. Disponível em: https://cartografiasentimental.wordpress. com/2011/01/18/o-significado-politico-nas-trouxas-ensanguentadas-de-barrio/. Acesso em: 10 abr. 2020. 
AYERBE, Nerea. Documenting the Ephemeral: reconsidering the idea of presence in discussions on performance. Revista Brasileira de Estudos da Presença, UFRGS, Porto Alegre, v. 7, n. 3, p. 551-572, 2017. Disponível em: http://dx.doi.org/10.1590/2237266069648. Acesso em: 26 out. 2020.

BUNTNIX, Gustavo. Lava la bandera: el Colectivo Sociedad Civil y el derrocamniento cultural de la dictadura en el Perú. Emisférica, New York, v. 3, n. 1, n.p., 2006.

CADÚS, Eugenia. Re-montar Jirones de Historia: la danza y la memoria de la última dictadura cívico-militar argentina. Revista Brasileira de Estudos da Presença, UFRGS, Porto Alegre, v. 10, n. 3, 2020. Disponível em: https://doi.org/10.1590/2237266091712. Acesso em: 26 out. 2020.

COSTA, André Oliveira; MOSCHEN, Simone Zanon. Psicanálise e educação: os paradoxos da alteridade. Educação \& Realidade, v. 38, n. 2, p. 433-433, 2013.

CUETO RÚA, Santiago. Demandas de justicia y escrache en HIJOS La Plata. Trabajos y Comunicaciones, Buenos Aires, v. 36, n. 36, p. 165-183, 2010.

DIÉGUEZ CABALLERO, Ileana. Cenários liminares: teatralidades, performances e política. Uberlândia: EDUFU, 2011.

DUGGAN, Patrick; WALLIS, Mick. Editorial: On Trauma. Performance Research, Abingdon-on-Thames, v. 16, n. 1, p. 1-3, 2011.

FELMAN, Shoshana. The scandal of the speaking body: Don Juan with J. L. Austin, or seduction in two languages. New York: Stanford University Press, 2003.

GORINI, Ulises. La rebelión de las Madres: historia de las Madres de Plaza de Mayo (1976-1983). La

Plata: EDULP, 2017.
ICLE, Gilberto. (Org.). Descrever o inapreesível: performance, pesquisa e pedagogia. São Paulo: Ed. Perspectiva, 2019.

LEVI, Primo. É isto um homem? Rio de Janeiro: Rocco, 1988.

LORENZO, Martín Fernández. Para não esquecer: a história das Mães da Plaza de Mayo, na Argentina. 2019. Disponível em: https://www.socialistamorena. com.br/para-nao-esquecer-a-historia-das-maes-da-plaza-de-mayo-na-argentina/. Acesso em: 8 abr. 2020.

MUZI, Carolina. La historia del pañuelo verde: cómo surgió el emblema del nuevo feminismo en Argentina - Infobae. 2018. Disponível em: https://www. infobae.com/cultura/2018/08/05/la-historia-del-panuelo-verde-como-surgio-el-emblema-del-nuevo-feminismo-en-argentina/. Acesso em: 9 abr. 2020.

OTTONI, Paulo. John Langshaw Austin e a Visão Performativa da Linguagem. DELTA: Documentação de Estudos em Lingüística Teórica e Aplicada, v. 18, n. 1, p. 117-143, 2002.

SCHECHNER, Richard. Performance studies: an introduccion, second edition. New York \& Londres: Routledge, 2013.

SPROTT, Fiona. "Last seen alive": Lacan, Louise Bell and $\mathrm{i}$ in a haunted house. Rupkatha Journal on Interdisciplinary Studies in Humanities, Calcutá, v. 5, n. 2, p. 303-313, 2013.

TAYLOR, Diana. Trauma and Performance: Lessons from Latin America. Pmla, New York, v. 121, n. 5, p. 1674-1677, 2006.

TAYLOR, Diana. O trauma como performance de longa duração. O Percevejo, Rio de Janeiro, v. 1, n. 1, p. 1-12, 2009. 
TAYLOR, Diana. Performance. Buenos Aires: Asunto Impreso Ediciones, 2012.

TAYLOR, Diana. O arquivo e o repertório: performance e memória cultural nas Américas. Belo Horizonte: Editora UFMG, 2013.

UNDRILL, Guy. Book Review. Performance Research, Abingdon-on-Thames, v. 5, n. 3, p. 133-137, 2000 .

Recebido: 30/10/2020

Aceito: $10 / 12 / 2020$

Aprovado para publicação: 18/04/2021

Este é um artigo de acesso aberto distribuído sob os termos de uma Licença Crea- tive Commons Atribuição 4.0 Internacional. Disponível em: <http://creativecommons.org/licenses/by/4.0>.

This is an open-access article distributed under the terms of the Creative Commons Attribution License 4.0 International. Available at: $<$ http://creativecommons.org/licenses/by/4.0>.

Ce texte en libre accès est placé sous licence Creative Commons Attribution 4.0 International. Disponible sur: <http://creativecommons.org/licenses/by/4.0>. 